\title{
Localising political party appeals
}

\author{
Annika Werner ${ }^{1}$
}

๑) European Consortium for Political Research 2020

\section{Book reviewed: \\ Are Politics Local? The Two Dimensions of Party Nationalization around the World}

Scott Morgenstern (Cambridge, Cambridge University Press, 2017), 299 pp. ISBN: 978-1-108-41 513-2 (Hardback) 978-1-108-40034-3 (Paperback)

Democratic political parties get categorised in manifold ways, for instance with reference to their size, ideology or roles in the political system. Yet, when it comes to their spatial focus in terms of representation, strategy and policy, we rather crudely identify some as regional parties and assume that all other parties focus on the whole nation in a uniform manner. Scott Morgenstern's book challenges this limited vision and provides us with the tools for a more sophisticated understanding. The book investigates to what extent individual parties' voter bases are localised or nationalised and thus brings political geography into the study of parties. Using readily available district-level voting data in innovative ways, Morgenstern shows a way of analysing parties' behaviour and their role in the democratic state from a novel perspective.

At the heart of Morgenstern's book are the concepts of static and dynamic nationalisation, which he uses to decide whether a party is situated mainly at the national or at the local level. Static nationalisation is characterised as "the degree of homogeneity in a party's vote across a country at a particular point in time" (p. 5). Thus, this concept measures how evenly distributed or locally clustered a party's voters are. Dynamic nationalisation, on the other hand, measures whether voter swings for or against a party occur evenly across all districts, or can change in one district independent of the vote share in other districts. These two concepts taken together result in four ideal party types (p. 31): at opposite ends of this spectrum are nationalised parties with evenly distributed voters who all swing together and locally focused parties with voters clustered in a few districts that behave differently to each other. The two in-between types are defined as unbalanced parties, whose voters cluster in a few districts but shift together, and

Annika Werner

annika.werner@anu.edu.au

1 Australian National University, Canberra, Australia 
unstable parties, whose voters are evenly distributed over the country but have localised tendencies to swing.

This conceptualisation of party types is a major contribution of this book and will be of interest for scholars working on patterns of party development and party behaviour. Morgenstern takes great care in setting up these concepts, devoting a whole chapter to their operationalisation and measurement decisions. While the categorisation suffers from the usual difficulty in defining thresholds, there are relatively few cases that do not fall clearly into one of the four types, and the underlying two dimensions could be used as continuous measures. The fact that the measurement is based on available district-level voting data also makes it relatively easy to implement.

The empirical illustration and following analysis of this party typology is based on Morgenstern's categorisation of over 200 parties from established democracies all over the world and for the period of 1990-2010. He finds that there are some regional patterns, the most prominent of which are that Western European parties tend to be more nationalised and that the newer democracies of Eastern Asia and Latin America vary widely in their levels of nationalisation and localisation. Most interestingly, Morgenstern finds a lot of variation within countries. Significantly, this variation goes beyond the identification of known regional parties. Indeed, most countries include parties of various types (p. 93).

Analysing patterns of party nationalisation, Morgenstern finds that parliamentary and centralised systems tend to produce more nationalised parties and that ethnic heterogeneity leads to localised parties. This confirms what we know about these factors influencing the likelihood of regional parties, as well as the relative strength of central parties and local MPs. Additionally, when investigating what effects different levels of party nationalisation might have, Morgenstern broadens the scope to a more general and mainly theoretical discussion about how political geography affects representation and accountability (chapter 7). Morgenstern provides first insights into the empirical reality by focusing on some countries as examples to argue that a party's relative nationalisation or localism has an effect on retrospective voting and, thus, on party strategies. A broader systematic comparative analysis could shed substantial light on the mechanisms and possible intervening variables. Finally, when focusing on the effects of nationalisation on co-operation between legislators of the same party, Morgenstern makes an important contribution when he shows through comparison how this mechanism is present but predisposed by the institutional set-up.

The well-developed and thoroughly tested measures of static and dynamic nationalisation that Morgenstern offers in Are Politics Local? allow for variation of parties within countries and over time, going beyond a static categorisation of party types into a more fluid idea of 'regional' and 'national' parties. This is a major contribution of this book and will be useful for a wide range of studies on party development and party behaviour because it allows us to use more precise party characteristics in our models. In addition, it also allows us to measure party systems along a scale from 'purely nationalised' to 'purely localised'. This will 
further enhance our understanding of how ethnic fragmentation and (also latent and non-ethnic) regional identities are represented in party systems and affect politics at large.

Dr. Annika Werner is a Senior Lecturer at the School of Politics and International Relations, Australian National University. Her research focuses on party behaviour, representation and public attitudes in the democracies of Europe and Oceania. 